\title{
Possibilidades nos Modos de Tratar a População em Situação de Rua*
}

\author{
William Azevedo de Souza ${ }^{1}$ \\ ${ }^{1}$ Universidade Estadual Paulista Júlio de Mesquita \\ Filho, SP, Brasil.
}

\author{
Abílio da Costa-Rosa ${ }^{2}$ \\ ${ }^{2}$ Universidade Estadual Paulista Júlio de Mesquita \\ Filho, SP, Brasil.
}

Silvio José Benelli ${ }^{3}$

${ }^{3}$ Universidade Estadual Paulista Júlio de Mesquita Filho, SP, Brasil.

\begin{abstract}
Resumo: O número de pessoas em situação de rua na cidade de São Paulo e no Brasil tem aumentando constantemente; antes, um fenômeno localizado em grandes centros urbanos, atualmente, pode ser observado em diversas cidades. Este artigo trata do trabalho na Assistência Social com esse fenômeno social, a partir da práxis do trabalhador-intercessor, abordando as singularidades dos sujeitos e do seu território. Verifica-se a ausência de pesquisas realizadas por trabalhadores e a prevalência de textos que abordam aspectos da vida dessa população: quem são, como vivem e como são vistas. O objetivo foi analisar criticamente a realidade em que os serviços de Assistência Social estão sendo implantados e propor modos de tratar os sujeitos, considerando a sua subjetividade, de maneira que se possibilite ajudá-los a se situar em relação à situação complexa vivida, além de construir o acesso a direitos sociais. Para isso, utilizou-se o Dispositivo Intercessor (DI), uma modalidade de ação que permite pensar e construir modos de agir e de interceder na realidade dos sujeitos e das instituições, bem como produzir saber e conhecimento, com base nessa ação. Observa-se que o posicionamento do trabalhador frente às demandas e seus instrumentos teórico-técnicos, DI, fazem a diferença na análise do contexto social, na abordagem da complexidade dos casos e na construção de caminhos que ajudem os sujeitos a acessar direitos. Apesar de tais direitos já serem garantidos por lei, constata-se que, em muitos casos, o acesso a eles precisa ser efetivamente construído, o que demanda intercessões entre os sujeitos e os serviços territoriais.
\end{abstract}

Palavras-chave: Assistência Social, População em Situação de rua, Dispositivo Intercessor, Sistema Único de Assistência Social, Práxis.

\footnotetext{
* Este artigo foi escrito a partir de uma experiência profissional e acadêmica de um dos autores, trabalhador da área da Assistência Social de um município do estado de São Paulo, enquanto integrante de uma equipe de um Centro de Referência Especializado da Assistência Social (CREAS), contando com a colaboração dos demais autores, professores universitários, na concepção e produção do texto.
} 


\title{
Possibilities in the Ways of Treament of Homeless People
}

\begin{abstract}
The number of people living in the streets of São Paulo and Brazil has been steadily increasing; a phenomenon that was before located in large urban centers, can be currently observed in several cities. This paper discusses the work in Social Assistance with homeless people, based on the praxis of the intercessor-worker, explaining the singularities of subjects and their territory. There is an absence of researches conducted by workers and a prevalence of papers that approach the life aspects of this population: who they are, how they live, and how they are seen. The objective was to critically analyze the reality in which the Social Assistance services are being implemented and propose ways of treating subjects, considering their subjectivity, so they get better situated in relation to the complex situation they live, and build access to social rights. In order to do so, the Intercessor Device (ID) was used, a modality of action that allows us to think and construct ways of acting and interceding in the reality of subjects and institutions, as well as produce knowledge and unconscious knowledge from this action. It is observed that the position of the worker in front of the demands and his theoretical and technical instruments, ID, make the difference in the analysis of the social context, in the approach of the complexity of the cases and in the construction of paths that allow subjects to access social rights. Although such rights are already guaranteed by law, it is verified that, in many cases, access to them must be effectively constructed, which demands intercessions between the subjects and the territorial services.
\end{abstract}

Keywords: Social Assistance, Homeless, Intercessor Device, Single Social Assistance System, Praxis.

\section{Posibilidades en los Modos de Tratar a la Población en Situación de Calle}

Resumen: El número de personas en situación de calle en la ciudad de São Paulo y en Brasil ha aumentado constantemente; antes, un fenómeno localizado en grandes centros urbanos, actualmente, puede ser observado en diversas ciudades. Este artículo trata del trabajo en la Asistencia Social ese fenómeno social, a partir de la praxis del trabajador-intercesor, abordando las singularidades de los sujetos y de su territorio. Se constata la ausencia de investigaciones realizadas por trabajadores y la prevalencia de textos que abordan aspectos de la vida de esa población: quiénes son, cómo viven y como son vistos. El objetivo fue analizar críticamente la realidad en que los servicios de Asistencia Social están siendo implantados y proponer modos de tratar a los sujetos, considerando su subjetividad, de modo que se posibilite ayudarlos a situarse en relación a la situación compleja vivida, además de construir el acceso a los derechos sociales. Para ello, se utilizó el Dispositivo Intercesor (DI), una modalidad de acción que permite pensar y construir modos de actuar y de interceder en la realidad de los sujetos y de las instituciones, así como producir conocimiento y conocimiento inconsciente, con base en esa acción. Se observa que el posicionamiento del trabajador frente a las demandas y sus instrumentos teórico-técnicos, DI, marcan la diferencia en el análisis del contexto social, en el enfoque de la complejidad de los casos y en la construcción de caminos que posibiliten a los sujetos acceder a derechos sociales. A pesar de tales ya se garantizan por ley, se constata que, en muchos casos, el acceso a ellos necesita ser efectivamente construido, lo que demanda intercesiones entre los sujetos y los servicios territoriales.

Palabras clave: Asistencia Social, Población en Situación de calle, Dispositivo Intercesor, Sistema Único de Asistencia Social, Praxis. 
O tema tratado nestas linhas versa sobre o trabalho no Sistema Único da Assistência Social - SUAS (Brasil, 2005, 2012), com pessoas em situação de rua, em um município de grande porte do estado de São Paulo, o qual passou pelo processo de implantação dos serviços especializados de atendimento às pessoas em situação de rua e de abordagem social (Brasil, 2011; 2013a). Destacaremos os impasses e desafios na construção dessa práxis, mostrando parte da realidade vivenciada pelos sujeitos no cotidiano da rua e na busca pela sobrevivência, uma vez que a realidade sempre se mostra mais complexa do que aquilo que imediatamente conseguimos apreender dela.

A literatura nacional apresenta importantes trabalhos sobre pessoas em situação de rua (Borysow, \& Furtado, 2013; Bursztyn, 2000; Escorel, 1999; Justo, 2011; 2012; Mattos, 2006; Mattos, \& Ferreira, 2004; Nasser, 2001; Rosa, 1995; 2005; Silva, 2005; Varanda, 2003; Vieira, Bezerra, \& Rosa, 1994), os quais retratam elementos teóricos de grande relevância, imprescindíveis para a atuação dos trabalhadores. Entretanto, verificamos a inexistência de pesquisas que discutam a práxis na Assistência Social com pessoas em situação de rua, a partir de um olhar não disciplinar e que considerem a singularidade dos sujeitos.

Existem também outros trabalhos de igual importância que abordam temas mais específicos, no âmbito das pessoas que moram na rua, tais como a violência (Valencio, Cardoso, Siena, \& Marchezini, 2008), quem são, como vivem e como são vistas (Mattos, \& Ferreira, 2004), o sofrimento psíquico (Brito, 2012; Lovisi, 2000), o modo de viver (Félix-Silva, Sales, \& Soares, 2016), a loucura (Albuquerque, 2009; Ferraz, 2000), a mulher em situação de rua (Tiene, 2004), o idoso em situação de rua (Mattos, \& Ferreira, 2005), o uso e o abuso de álcool e de outras drogas (Botti et al., 2010), o processo de saúde e adoecimento (Rosa, Cavicchioli, \& Brêtas, 2005), o processo de subjetivação (Villamarim, 2009) e a construção da corporeidade na rua (Frangella, 2004). Geralmente, quando os estabelecimentos de Assistência Social ou os trabalhadores são abordados, nesses textos, destacam-se mais o caráter da gestão de risco (Castel, 1987; Martinez, Pereira, Barbosa, Oliveira, \& Pazzin, 2014), o controle e a docilização dos corpos (Bar- bosa, 2017; Foucault, 2009), as facetas da instituição total (Goffman, 2001, Justo, 2011; 2012), nos casos de acolhimento institucional, ou os impactos e os efeitos estruturais do modo capitalista de produção.

Por outro lado, no dia a dia dos serviços da Assistência Social que atendem às pessoas que estão vivendo nas ruas, encontramos sujeitos com demandas complexas de violação de direitos, as quais perpassam diretamente ou tangenciam muitos dos temas abordados por esses pesquisadores, nos quais se somam a história singular do sujeito, a do trabalhador e a rede comunitária e de serviços do território ${ }^{1}$. É um campo complexo e atravessado por elementos de diversas ordens, dentre os quais ressaltamos a imprevisibilidade, pois não se pode saber $a$ priori o que poderá acontecer, quais demandas surgirão ou se serão desveladas, no decorrer dos atendimentos. Por isso, o caminho construído para um caso poderá não servir para outro; entretanto, alguns elementos e instrumentos têm potência de subsidiar a trajetória dos sujeitos, tanto dos trabalhadores quanto das pessoas em situação de rua (Souza, 2015).

Trabalhamos com a hipótese de que os trabalhos que partem de uma realidade em movimento e levem em conta as singularidades dos sujeitos, dos serviços de Assistência Social e do território, têm mais potência para subsidiar os profissionais acerca dos impasses e desafios aos quais são interpelados a dar soluções. Logo, o objetivo principal do nosso trabalho é analisar criticamente a realidade em que os serviços de Assistência Social de uma cidade do estado de São Paulo estão sendo implantados e/ou implementados, e propor modos de interceder com as pessoas em situação de rua, consideradas em situação de "vulnerabilidade e risco social", com seus direitos violados, já que o número de pessoas em situação de rua tem aumentado em diversas cidades do Brasil (Souza, 2015).

Resumindo: trataremos, nas próximas linhas, sobre o modo de posicionamento do trabalhador-intercessor e sobre o conjunto de ofertas e possibilidades transferenciais que uma cidade de grande porte pode ou não disponibilizar para os sujeitos que foram empurrados para as bordas do consumo e da sociedade, e que retornam como se fossem o con-

${ }^{1}$ Conforme Santos (2002), o território é um local dinâmico e vivo, onde se atualizam processos sociais, subjetivos, econômicos e políticos, cheio de transformações e atravessamentos. 
teúdo inconsciente (recalcado), passando a habitar os espaços públicos e os centros das cidades, desvelando aquilo que se quer esconder, a pobreza. Assim, os resultados principais se apresentam na produção de formas de tratar e atender às pessoas em situação de rua, tendo em vista a singularidade dos sujeitos e o seu território, além de mostrar os impasses que os sujeitos enfrentam, ao tentar acessar direitos básicos.

\section{O Dispositivo Intercessor ${ }^{2}$}

A partir da práxis de um trabalhador do Centro de Referência Especializado da Assistência Social (CREAS), o qual denominaremos trabalhador-intercessor, este trabalho é caracterizado por adotar como referenciais teórico-técnicos e ético-políticos de análise e intercessão o materialismo histórico (Marx, 1984; 2004), a análise institucional (Lourau, 1975), a filosofia da diferença (Deleuze, 1992) e a psicanálise do campo de Freud e Lacan (Freud, 1988; 1996; Lacan, 1992; 2003).

Trata-se de uma pesquisa qualitativa e transdisciplinar, cujo objeto de análise é a própria experiência do trabalhador. Alguns fragmentos de casos atendidos ou acompanhados foram utilizados para exemplificar situações do cotidiano do trabalho, as quais foram selecionadas apenas para demonstrar os modos como os impasses e os desafios se atualizam, no cotidiano dos estabelecimentos de Assistência Social. Logo, o "objeto" de pesquisa não se refere diretamente aos sujeitos atendidos, mas aos modos de tratar as pessoas em situação de rua. Ainda assim, as pessoas cujos relatos de atendimento aparecem neste texto, ou seja, na intercessão-pesquisa, consentiram em participar da pesquisa e assinaram o Termo de Consentimento Livre e Esclarecido (TCLE), após o encerramento dos atendimentos ou dos acompanhamentos, uma vez que o pedido prévio para emprego dos relatos de seu atendimento poderia influenciar ou atrapalhar o andamento dos casos.

O conteúdo para a intercessão-pesquisa foi retirado das anotações do diário de intercessão (diário de campo), instrumento de trabalho que auxilia o intercessor na sua atuação cotidiana. Por conseguinte, o trabalhador-intercessor é um trabalhador do SUAS que reflete sobre a sua experiência de trabalho e decide, em função dela, produzir conhecimento. É um trabalhador que procura transformar a sua práxis em conhecimento. Os sujeitos dos relatos e histórias que aparecem na pesquisa são "usuários" do SUAS, pessoas em situação de rua com idade acima de 18 anos, as quais demandavam acesso a direitos socioassistenciais. A pesquisa foi aprovada pelo Comitê de Ética em Pesquisa da Faculdade de Ciências e Letras da Universidade Estadual Paulista Júlio de Mesquita Filho (Unesp), campus de Assis, no 045495/2013.

Para dar conta dessa empreitada, utilizamos como "metodologia" de ação e de produção de conhecimento o Dispositivo Intercessor (DI). Trata-se de um dispositivo de intercessão que possibilita ao trabalhador operar na práxis com os sujeitos e construir maneiras de agir e de interceder em sua realidade e na dos estabelecimentos institucionais, bem como no modo de produção de conhecimento de estatuto epistemológico (Costa-Rosa, 2007; 2008; 2013; 2015). O DI possui muitas similaridades com o método psicanalítico, tendo como diferencial a busca da transformação da realidade pelos sujeitos envolvidos na ação, a partir da intervenção do trabalhador-intercessor (Stringheta, \& Costa-Rosa, 2007).

O DI pode ser dividido em dois momentos específicos e inter-relacionados. O primeiro diz respeito a um modo de intercessão na práxis (trabalhador-intercessor), realizado por meio do contato direto com os sujeitos nos atendimentos, nos acompanhamentos, nas abordagens, nos grupos, nas visitas domiciliares, nas oficinas e em outras atividades. Nesses encontros do trabalhador com os sujeitos, ocorre a produção de um saber que se consuma no ato da sua produção e que apenas pode ser apropriado pelos sujeitos envolvidos nessa relação de atendimento. A construção desse saber está inteiramente relacionada com as condições de sua produção, ou seja, com a relação transferencial (vínculo) que os sujeitos têm com o trabalhador e com as formas com que ele se posiciona e responde às demandas que lhe são endereçadas.

No segundo momento, é possível produzir conhecimento sobre o processo de produção dessa práxis (momento primeiro), etapa na qual o trabalha-

\footnotetext{
2 "Dispositivo" é um conceito da Análise Institucional Francesa que pode ser considerado um operador ou um modo de produzir intercessões, e, por isso, pode produzir o instituinte e o instituído; já o “Intercessor” vem do conceito de intercessores, de Deleuze (1992), relido a partir das teorizações do campo de Freud e Lacan.
} 
dor refletirá criticamente sobre o percurso efetivado à luz da teoria e de referenciais transdisciplinares. Portanto, a pesquisa propriamente dita ocorre apenas nesse segundo momento. $\mathrm{O}$ material empregado na pesquisa consiste nas anotações do diário de intercessão provenientes das memórias do trabalhador-intercessor, articulando-se com informações de documentos institucionais oficiais, literatura sobre o campo da Assistência Social e sobre a população de rua. No caso da presente pesquisa, todos esses materiais serviram como base para a construção de um texto que foi submetido para análise e sugestões de outros trabalhadores e pesquisadores.

Em relação à utilização dos registros realizados nesse formato e a sua validade e importância, Mezan (2002) afirma que as anotações do psicanalista, em nosso caso, o próprio trabalhador-intercessor, feitas a posteriori, têm total legitimidade, pois o raciocínio analítico dificilmente se baseia em um fato isolado, mas no conjunto de elementos que apresentam similaridades, além de a transcrição literal das palavras ter pouca importância, quando comparada ao sentido geral do discurso. Na pesquisa qualitativa, o conhecimento tem um caráter interpretativo, não sendo produzido logo após a apreensão dos fatos ou eventos, portanto, para ser construído, precisa de um processo de atribuição de sentido sobre o que foi visto e vivido, por parte do pesquisador. Os indicadores produzidos ganham sentido por meio da integração, construção e reconstrução de sucessivas configurações interpretativas (Gonzalez-Rey, 2002).

A produção de um saber cujo pano de fundo é complexo e mutante tem como funcionalidade ajudar os sujeitos a descobrir como se ajudar (Costa-Rosa, 2015), resolver seus impasses cotidianos e subsidiar a práxis de outros trabalhadores. Seria como um guia para a ação, um conhecimento que parte da complexidade da realidade (Morin, 2005), o que, para Santos (2006), seria um conhecimento prudente para uma vida decente. Nesse modo de fazer pesquisa, a história, o protagonismo e os conhecimentos dos próprios sujeitos, na resolução dos impasses, são valorizados, uma vez que tanto o trabalhador quanto os usuários têm um saber sobre aquilo que eles mesmos executam.

\section{Resultados e discussão}

Denominaremos X o município onde foi realizada a intercessão-pesquisa. Acreditamos que muitos dos eventos aqui abordados e problematizados podem apresentar similaridades aos que costumam ocorrer em outras cidades que também estão no processo de implantação de serviços para as pessoas em situação de rua ou que já atendem a essa população. Assim, destacaremos primeiramente dois pontos a serem considerados no trabalho e na implantação dos serviços: a localização e as ofertas disponíveis pela instituição.

No caso da localização, quanto mais próximo ao centro da cidade e/ou do fluxo de pessoas, mais fácil é o acesso e a criação de vínculos de pertencimento e de referência das pessoas em situação de rua com a equipe dos CREAS ou Centro Pop ${ }^{3}$, porque, segundo Souza (2015), a distância tende a viabilizar ou inviabilizar a frequência das pessoas a esses estabelecimentos. O segundo ponto é o conjunto de ofertas disponibilizadas pelo estabelecimento e que podem interessar aos sujeitos, fazendo-os se deslocarem na direção de um local capaz de resolver os seus problemas imediatos. Por exemplo, a localização do CREAS da cidade $\mathrm{X}$ era um pouco afastada do centro da cidade, o que causava alguns empecilhos, tanto para os sujeitos quanto para a equipe. O número de abordagens a pessoas em situação de rua era oito vezes maior do que o número de sujeitos que procuravam o atendimento na sede do CREAS.

Por outro lado, a rua oferecia um conjunto de outras possibilidades para os sujeitos que tentavam satisfazer suas demandas imediatas e se organizar, a partir de uma rede singular, construída por eles mesmos e que envolvia casas de munícipes, bares, restaurantes, lojas, igrejas, locais que ofertavam trabalhos sem carteira assinada, grupos que distribuíam alimentos na rua, dentre outras. A própria população de rua também entrava como um componente importante, pois geralmente assumia uma posição acolhedora com outras pessoas que acabavam de chegar à cidade, estando na mesma situação que eles. É importante salientar que a rede construída pelo sujeito na rua pode incluir ou não os serviços de Assistência Social ou de outras políticas públicas, pois isso

\footnotetext{
${ }^{3}$ Centro de Referência Especializado para População em Situação de Rua, diferenciando-se dos serviços de Acolhimento Institucional (abrigo, albergue e casa de passagem), com oferta de acolhimento, atendimento, acompanhamento, informação, convivência, espaço para higienização pessoal, lavagem de roupa, guarda de pertences (Brasil, 2011).
} 
depende essencialmente do que é e de como foi ofertado, principalmente da representação que se tem do estabelecimento, no território.

O trabalho em rede (intersetorial) é essencial para o atendimento às pessoas em situação de rua, especialmente quanto ao direcionamento dado aos casos. De acordo com nossa experiência, os trabalhadores dos estabelecimentos de outras políticas públicas tendem a pensar que as pessoas em situação de rua são um público específico da Assistência Social, motivo pelo qual o Comitê Intersetorial de Monitoramento da População em Situação de Rua se localiza na Secretaria de Direitos Humanos da Presidência da República. Não era raro ouvirmos de alguns trabalhadores de outras secretarias (educação, saúde, segurança, trabalho e habitação) que as pessoas em situação de rua são "casos sociais", ou seja, exclusivos da Assistência Social, ou até mesmo ouvir dentro da própria Secretaria da Assistência Social que essas pessoas deveriam ser atendidas apenas em um estabelecimento (CREAS ou Centro Pop) e não em outros estabelecimentos da Assistência Social.

As outras políticas têm se eximido de sua responsabilidade para com a população de rua. Em razão disso, é importante que o trabalhador-intercessor conheça a fundo o papel do Estado, do terceiro setor, da sociedade civil, da iniciativa privada e das diferentes instituições e estabelecimentos do território, principalmente o da Assistência Social e das outras políticas com as quais faz interface. Esse conhecimento do contexto institucional favorece a compreensão do respectivo papel do profissional, o que é uma condição para se produzirem intercessões no instituído do discurso oficial e nas práticas, nos diferentes planos. Essas ações, realizadas segundo a lógica e os princípios do DI, oferecem a possibilidade de que se aproveitem as brechas do instituinte (Lourau, 1975), isto é, aberturas que propiciam a criação do novo, sendo que, por hipótese, "existem mais brechas abertas do que estratégias para ocupá-las” (Costa-Rosa, 1987).

O intuito é ocupar as brechas e trabalhar com os sujeitos (população do território, estando ou não na rua), para reivindicar e cobrar a parte que cabe a cada setor dos estabelecimentos públicos no atendimento às pessoas em situação de rua, além da construção de novos estabelecimentos e de melhorias nos já existentes. Considerando o plano institucional intersetorial, o trabalho em rede é imprescindível, posto que, sem ele, as ações em geral e os atendimentos ficam centrados em um único estabelecimento ou equipe específica, geralmente da Assistência Social ou da Saúde.

O município onde a práxis de intercessão-pesquisa ocorreu é composto de vários territórios, com diversas redes, as quais, dependendo do caso, podiam ser compostas por amigos, vizinhos, comunidade, estabelecimentos da Assistência Social, dentre outros. A rede construiu-se de acordo com a demanda e com as possibilidades existentes no território, mas sempre havia a necessidade de implementá-la, por exemplo, com a rede de estabelecimentos da Saúde ou com a rede de serviços da Assistência Social, além de estabelecimentos do território, como escolas, igrejas, Unidades Básicas de Saúde (UBS), Unidades de Pronto Atendimento (UPA), Centros de Referência da Assistência Social (CRAS), CREAS, abrigos, Centro de Atenção Psicossocial II (CAPS) e outros.

\section{Um caso para ilustrar o funcionamento da rede e sua (des)responsabilização}

Um homem com cerca de 30 anos foi encontrado por uma senhora nas proximidades de uma estrada perto do município X. Ao vê-lo, ela rapidamente diagnosticou nele algum "problema de cabeça", já que estava revirando o lixo e, aparentemente, estava perdido e confuso. Relata que imaginou que ele deveria ter família e que precisava receber tratamento médico. Levou-o ao Pronto-Socorro, onde o diagnóstico dado pelo saber médico foi que ele estava com transtorno psicótico e, além de outros transtornos, apresentava deficiência intelectual moderada, pois ele não sabia dizer o próprio nome ou de algum familiar, telefone, bairro, rua ou casa onde morava. Foi ficando no Pronto-Socorro e logo começou a criar vínculo com os funcionários, que o nomearam de Alberto ${ }^{4}$. Após passar mais de um mês nesse estabelecimento, sem que houvesse nenhuma informação sobre sua família e seu endereço ou alteração no quadro clínico, o sujeito recebeu alta hospitalar. Todavia, segundo o hospital, ele tinha pouca autonomia e precisaria de alguém que se responsabilizasse por seus cuidados. A equipe de abordagem do CREAS foi acionada. No primeiro

${ }^{4}$ Por motivos éticos e de sigilo, os nomes tanto dos sujeitos como do município foram alterados. 
momento, o trabalho foi construído em conjunto ao Pronto-Socorro, discutindo o caso, construindo alternativas e tentando ajudar o Alberto a se lembrar de alguma informação que desse uma direção.

O hospital estava com todos os leitos preenchidos e com uma fila grande de pessoas que esperavam uma vaga para serem internadas. A equipe de abordagem articulou com um abrigo a possibilidade de acolher Alberto, até que localizássemos sua família. Um dos integrantes da equipe levou-o para um abrigo no município vizinho, mas, após alguns dias, fomos avisados de que o abrigo pararia de atender a pessoas em situação de rua. Precisávamos encontrar outro lugar para Alberto ficar. Os outros dois abrigos próximos ao nosso município não estavam dispostos a recebê-lo, pois, com os diagnósticos que havia recebido e a suposta deficiência intelectual, ele exigia cuidados e uma atenção redobrada que os estabelecimentos alegavam ter dificuldades em ofertar. Entramos em contato novamente com o Pronto-Socorro e perguntamos se seria possível acolher Alberto por um período de tempo maior, até encontrarmos sua família ou outro local que o acolhesse. A resposta foi de que não haveria essa possibilidade, pois, mesmo tendo leitos vagos, a lógica do hospital era de que, após a alta, ele não poderia voltar, a não ser que estivesse doente.

Continuamos a buscar pela família de Alberto e por estabelecimentos que pudessem acolhê-lo ou atendê-lo, em suas especificidades, mas todos estavam lotados ou com imensas filas de espera. Acionamos o Ministério Público, levamos Alberto até a Delegacia de Polícia, na qual fomos informados que o boletim de ocorrência só era feito no caso de pessoas desaparecidas e, como ele não estava desaparecido, não tinha nome, não sabia nenhuma informação sobre si mesmo, nem seu endereço, nada poderiam fazer naquele momento. Pesquisamos em diversos sites de pessoas desaparecidas, enviamos a foto para diversos estabelecimentos do município e de outros municípios vizinhos, contudo, não conseguimos nenhuma informação. Tentamos fazer com que ele fosse atendido no CAPS II e no Centro de Atendimento às pessoas com deficiência. Em cada um desses centros, disseram-nos que o lugar dele não era lá. No CAPS II, argumentaram que ele tinha deficiência intelectual e que eles apenas atendiam a pessoas com "transtorno mental"; no centro de atendimento às pessoas com deficiência, enfatizaram a mesma coisa, mas de forma invertida. Portanto, nenhum outro esta- belecimento da rede se responsabilizou por Alberto e ele não pôde ser atendido por ninguém da rede, com exceção da equipe de atendimento às pessoas em situação de rua. Todas as outras políticas se eximiram da responsabilidade pelo atendimento. No percurso que fizemos pela rede, tentávamos interrogar os estabelecimentos e os trabalhadores a respeito das ofertas que tinham para as pessoas em situação de rua e para Alberto. Refletíamos sobre nossas ações e a direção que tomávamos, a cada dia.

Na perspectiva da psicanálise, segundo Freud (1996), teoria e prática coincidem, quando se trata da construção dos casos. Aprendemos fazendo, mas não sem passar pelas dificuldades que a realidade impõe; o imaginário social, atualizado nos estabelecimentos da rede, continha concepções e (pre)conceitos sobre o viver na rua. As intercessões pretenderam desconstruir muitas dessas ideias, práticas e saberes, especialmente quanto à exigência de se apresentar documentação para ser atendido na rede de Saúde, ter endereço fixo, ou sair primeiro da rua para iniciar o tratamento de álcool e/ou de outras drogas. Os modos de lidar com a situação evidenciados pela rede de atendimento de pessoas em situação de rua foram sendo construídos à medida que, em seu fazer, a equipe ia se apropriando do saber, aprendia com a práxis no contato com as pessoas, com o território e com as suas histórias. Aprendíamos com o desenrolar dos casos, e em cada um havia uma história e uma problemática específica, logo, era necessário um direcionamento diferente a ser tomado para encaminhar cada caso.

Geralmente, quando os sujeitos chegam aos serviços, são portadores de uma demanda de auxílio, sendo que, por parte do trabalhador-intercessor, a maneira de "responder" a ela faz toda a diferença. $\mathrm{Na}$ concepção psicanalítica, a demanda “[...] consiste em fazer crer que ela é formulada para ser satisfeita. $\mathrm{Na}$ medida em que a demanda articula pela linguagem as necessidades do sujeito, ela promove o desprendimento dos objetos que, só suposta e aparentemente, seriam por ela demandados" (Elia, 2010, p. 55). Logo, é formulada para não ser satisfeita, pois os sujeitos querem sempre outra coisa, a qual nunca coincide com aquilo que demandam. Trata-se, aliás, de querer sempre mais do que buscam, nos estabelecimentos.

Essa demanda de auxílio não vem separada de uma demanda de saber, expressa como uma demanda de conhecimento que possa resolver o impasse ou 
satisfazer a encomenda. Nossa hipótese de trabalho é de que, nessa demanda de conhecimento, podemos introduzir (quando isso for possível, e for o caso) também uma demanda de saber, a qual permita ao indivíduo implicar-se como sujeito na situação mais ampla que foi a causa da situação atual. Consideramos possível que essa interrogação sobre aspectos mais amplos da situação vivida leve o sujeito a visualizar algumas das contradições importantes que $o$ atravessam, abrindo possibilidades para que, aos poucos, ele possa ir deixando o papel de coadjuvante, a fim de assumir o papel de protagonista. Em outras palavras: com isso, suspendendo qualquer resposta-tampão da nossa parte (Corbisier, 1992), os indivíduos poderiam produzir algo para além do que buscam, de modo imediato, poderiam fazer surgir demandas latentes e não apenas as manifestas, transformando a encomenda em demanda.

Nesse caso, é necessário pensar que um trabalhador situado em uma posição de intercessor junto aos sujeitos os quais fazem seus pedidos como encomendas e que esperam que elas sejam imediatamente respondidas, teria como posição básica e objetivo fundamental ajudá-los a se situarem de outro modo em relação à situação complexa vivida, da qual surgiram seus pedidos imediatos. Dessa forma, a função do trabalhador-intercessor não seria a de ser agenciador de suprimentos variados e exíguos, em torno dos quais se organiza fundamentalmente a própria Assistência Social, em sua versão mais comum, tanto no discurso oficial quanto na prática.

Uma das características diferenciais de um trabalhador-intercessor refere-se à construção de um vínculo de trabalho, cujo fundamento é o de que o sujeito que demanda e se queixa é o único que dispõe dos meios necessários para produzir as mudanças que lhe convêm. Promover tais mudanças, no caso das pessoas em situação de rua, deve incluir não apenas a interferência nas encomendas sociais, mas também as interferências no plano da demanda social. Nessa forma de trabalho, os sujeitos equacionam os seus próprios impasses. A instituição Assistência Social e seus estabelecimentos, bem como seus agentes, entram como coadjuvantes necessários nesse processo.
De acordo com as teorizações de Costa-Rosa (2011), para que os sujeitos assumam o lugar de protagonistas sociais no processo de produção de subjetividade singularizada, é imprescindível que antes sejam produzidos alguns remanejamentos essenciais, “[...] que dependerão da posição subjetiva em que eles se encontrem quando chegam em busca de ajuda. E na mesma medida esses remanejamentos decorrerão das ações daquele(s) que intercede(m) nas queixas e demandas [...]" (p. 750), isto é, nesse caso, os trabalhadores da Assistência Social.

Portanto, as ações tanto dos trabalhadores quanto dos sujeitos dependerão do modo como a Assistência Social e o CREAS são vistos pela população do território, principalmente pelos sujeitos que os utilizam e onde demandam ajuda; por exemplo, se são vistos como simples agências de fornecimento de suprimentos imediatos ou se poderiam funcionar também como espaços de interlocução, convívio e de parceria para o equacionamento de problemas. Sobretudo, as ações desses estabelecimentos e de seus trabalhadores dependerão do paradigma em que estão situados, podendo ser o Paradigma do Sujeito de Direitos (PSD) ou o Paradigma Caridoso Filantrópico Assistencialista $^{5}$ (PFCA) (Souza, 2015).

Um trabalhador situado na lógica e ética do PSD está necessariamente preparado para adotar uma posição que leve os sujeitos das demandas imediatas de suprimento a únicos detentores da possibilidade de equacionar algo relevante a respeito do que está em jogo em seus pedidos. O trabalhador, nesse caso, tem em mente que “[...] será interpelado inicialmente num lugar 'transferencial' imaginário-simbólico, e inevitavelmente terá o seu processo de trabalho profundamente influenciado pela forma real como estão organizados os processos de produção na instituição em que realiza a atenção" (Costa-Rosa, 2011, p. 751).

Assim, um sujeito chegou ao CREAS solicitando uma passagem para ir a uma cidade vizinha. Antes de responder à demanda de passagem, nós o interrogamos na tentativa de desvelar sua demanda ou de fazer surgir uma nova, latente. No decorrer do primeiro atendimento, contou que foi para a rua após perder o emprego e se desentender com o pai. Desde que saiu de casa, tem andado de cidade em cidade e, às vezes,

${ }^{5}$ Esse paradigma é a junção de um conjunto de diversos de práticas e saberes históricos - caridade, filantropia, assistencialismo e outros -, cuja característica principal é considerar o outro como objeto de ajuda ou caridade. 
fica na casa de amigos, em albergues, casas de acolhimento ou na própria rua. Relata que já viajou para os Estados Unidos, onde permaneceu por alguns anos, junto a seu antigo patrão, o qual, de maneira imperativa, o teria advertido de que, se continuasse com a prática da masturbação, morreria. O conflito com o pai, a compulsão à masturbação e o seu companheiro de estrada, Naru, rodeavam seu discurso e sua fala. Dizia que sofria muito e que esse companheiro sempre o acompanhava no "trecho" (expressão utilizada pela população de rua para se referirem aos espaços geográficos pelos quais transitam, entre as cidades). Dentre seus relatos, surgiam excertos como "Naru disse que era para eu me jogar embaixo do caminhão antes de vir para cá, assim, a masturbação pararia". Perguntei onde estava seu companheiro e ele respondeu: "Do seu lado". Obviamente, Naru só existia para ele. Perguntei se ele já ouvira falar do CAPS, ofertei-lhe a possibilidade de um local onde pudesse falar e ser atendido, um espaço no qual pudesse contar seu sofrimento do mesmo modo que falava para mim, e introduzi a ideia de um possível tratamento nesse estabelecimento. Os outros atendimentos seguiram nessa mesma direção, sem desconsiderar a subjetividade do sujeito, de sorte que a demanda pela passagem ficou em segundo plano.

Trabalhamos com a hipótese de que os sujeitos não buscam, nos estabelecimentos de Assistência Social, apenas o acesso a direitos e a garantia desses direitos, ou o acesso a benefícios, programas, serviços, projetos ou objetos que lhes faltem; eles procuram, de forma inadvertida, algo para além disso. A implicação subjetiva e sociocultural ${ }^{6}$ e o protagonismo são meios para levá-los a reivindicar e lutar por seus direitos. A hipótese de um trabalhador que opera como intercessor nas situações que lhe chegam é de que, quando vêm ao estabelecimento institucional, os indivíduos esperam encontrar o que buscam, porque têm grande necessidade disso, todavia, ao mesmo tempo, eles demandam mais do que recortam como necessidade imediata, do que encontram e também do que o estabelecimento pode ofertar.

O território apresenta uma diversidade de lugares onde as pessoas em situação de rua podem procurar atendimento e/ou negociar suas demandas imediatas por banho, alimentação, dinheiro, comida, lazer, pernoite, amizade, entre outras. Entretanto, o acesso a esses bens básicos, quando não são ofertados pelo poder público, vão depender principalmente da singularidade dos sujeitos e de como eles se articulam com a comunidade. A Assistência Social é apenas uma dessas possibilidades, e as igrejas, o comércio, com seus bares, postos de gasolina e restaurantes, a população em geral, de um modo ou de outro, também fazem parte dessa rede, já que ajudam a população de rua, por meio de doações, dinheiro, alimento ou somente com a escuta de fragmentos de suas histórias. No entanto, suas ações são finitas e restritas ao campo da caridade e da filantropia, ações pautadas no PCFA (Souza, 2015).

\section{Os modos como tratávamos a população em situação de rua}

Recebíamos solicitações de abordagem dos mais diversos lugares. Era comum que comerciantes, pessoas da comunidade e estabelecimentos públicos entrassem em contato, requisitando o "recolhimento" da pessoa em situação de rua. As solicitações vinham acompanhadas de uma série de queixas e reclamações, tais como: as pessoas em situação de rua estariam provocando incêndios, cometendo furtos, montando barracas, agredindo e ameaçando pessoas. Uma parte dessas reclamações condizia com a realidade, porém, no geral, almejavam apenas criar comoção e fazer com que o poder público (polícia, Guarda Municipal ou Assistência Social) agisse com rapidez, na resolução do problema do solicitante. Alguns dos problemas alegados não eram provocados pela população de rua, mas, mesmo assim, sua autoria lhe era atribuída.

Embora alguns solicitantes revelassem certa curiosidade sobre o modo de vida e as razões que levaram o indivíduo à rua, as conversas normalmente terminavam com pedidos de retirada das pessoas em situação de rua do local em que estavam. Em poucos casos, os pedidos eram para ajudar ou para manifestar preocupação com a condição em que a população em situação de rua se encontrava. Raramente o solicitante falava ou consultava as pes-

\footnotetext{
${ }^{6}$ Um modo de os sujeitos de se posicionarem frente às contradições que atravessam e pelas quais são atravessados, no caso do trabalhador da Assistência Social, envolve também o desejo de estar ali junto aos sujeitos e de apostar que é possível mudar a realidade, mesmo com todas as dificuldades e impossibilidades cotidianas.
} 
soas em situação de rua sobre sua abordagem por trabalhadores sociais.

Tentávamos responder a todos os solicitantes, geralmente de dois modos. Primeiro, explicando que o nosso trabalho não era recolher e nem retirar as pessoas da rua, porém, atendê-las em suas demandas, desde que isso estivesse dentro das possibilidades da equipe. Nossas ações tinham como direção construir e criar aberturas, para que os sujeitos pudessem acessar direitos constitucionais, sociais, socioassistenciais e humanos. No entanto, o instituído - caridade, filantropia e assistencialismo - apresentava-se com mais potência dentre as possibilidades ofertadas pelo próprio município, por meio de sua rede de serviços e pela forma de agir da comunidade, o que exigia dos trabalhadores ações instituintes que rompessem tais práticas. Segundo, tentávamos interrogar os solicitantes sobre as sugestões que eles teriam para que atendêssemos ao seu pedido de remoção, posto que nossa função era atender às pessoas em situação de rua e não simplesmente retirá-las da frente de casas ou estabelecimentos. Na maioria das vezes, a resposta à nossa interrogação era: "Vocês não têm um lugar para colocá-los? Uma internação ou uma casa?" De acordo com Sposati (1995), constantemente, os cidadãos demandam do Estado a remoção de pessoas em situação de rua que estão localizadas nas proximidades de suas residências.

Algumas pessoas que solicitavam as abordagens nem sequer queriam ouvir nossas explicações, somente ansiavam que aquele indivíduo que causava incômodo fosse retirado e levado para outro lugar. Não ligavam para saber sobre qual era o direito do outro, ambicionavam apenas que essas pessoas desaparecessem. Em termos de uma análise psicanalítica, é possível pensar que, nesses casos, o contato e o encontro com as pessoas em situação de rua levam a uma atualização de um imaginário de amor e ódio - expressando um misto de querer ajudar caritativamente, sentir raiva ou ignorar. Esses três modos de lidar com a população de rua, do ponto de vista de uma análise paradigmática e estrutural da Assistência Social e de suas funções sociais instituídas, tendem a levar ao pior, pois são atravessados pela ideologia da manutenção das relações sociais de dependência, exploração e dominação (Guareschi, 1996), na qual se deixa intacta a falta de acesso aos direitos sociais, já garantidos pela lei.
Conforme Mattos e Ferreira (2004), a população em situação de rua é vista pela sociedade como sendo composta por mendigos, loucas, vagabundas, sujas, bêbadas, coitadas e perigosas. Cada um desses (pre)conceitos acaba por formar uma concepção estigmatizada (Goffman, 1980) sobre essas pessoas, impedindo que elas sejam vistas de outra maneira, por exemplo, como um(a) trabalhador(a), uma pessoa honesta, um(a) desempregado(a), uma pessoa educada, um pai, uma mãe, um filho etc. Essa espécie de gestalt negativa projetada sobre as pessoas em situação de rua acaba produzindo um conjunto de práticas por parte da sociedade: neutralidade (fingir que não as vê ou que não existem), neutralização (tentativa de removê-las do campo de visão, de sorte a tentar simular a sua inexistência) e compaixão (tomá-las apenas como sofredoras, sem conexão com o conjunto social do qual fazem parte). Alterar esse imaginário social constitui um grande desafio a ser enfrentando pelos trabalhadores e pelos próprios sujeitos.

O contato da equipe de trabalhadores com as pessoas em situação de rua era denominado abordagem social, quando ocorria na rua, ou como atendimento, quando se dava na sede do estabelecimento. No primeiro caso, buscava-se conhecer a realidade das pessoas em seu território de circulação e referenciá-las nos estabelecimentos da rede setorial e intersetorial (Brasil, 2011; 2013a). Quando se tratava de operar na posição de trabalhador-intercessor, os primeiros passos incluíam o manejo da maneira de abordar os sujeitos e a construção do vínculo (transferência) que poderia garantir um mínimo campo de interlocução, pois o modo como esse encontro é realizado estabelece uma influência direta nos rumos dos atendimentos e no acesso aos direitos sociais.

Uma forma específica de configuração desse vínculo - a qual se pode nomear de transferência com implicação subjetiva (Costa-Rosa, 2000) - consiste numa situação na qual o sujeito delega ao trabalhador certos poderes para ajudá-lo, mas se incluindo, ao mesmo tempo, como protagonista das ações a serem realizadas para isso. Essa posição é aquela que pode tornar possíveis ações que chamamos de intercessões. Sublinhamos que essa modalidade de vínculo entre as pessoas em situação de rua e trabalhador-intercessor é construída desde os primeiros encontros, justamente porque se considera que o posicionamento inicial do trabalhador é um dos fatores decisivos quanto aos possíveis rumos do atendimento. Disso decorre 
que essa ação é mais do que a ação de um trabalhador comum, assentado no saber das disciplinas (Psicologia, Serviço Social, Pedagogia etc.).

O trabalhador-intercessor se define pela abertura para a superação, em sua práxis, da atitude disciplinar comum entre os técnicos com graduação universitária. Para tanto, ele se fundamenta em saberes pertencentes a campos transdisciplinares, tais como a psicanálise do campo de Freud e Lacan, o materialismo histórico de Marx, a análise institucional francesa, entre outros (Costa-Rosa, 2013). Quando abordávamos os sujeitos na rua e enunciávamos trabalhar na Assistência Social, a resistência das pessoas reduzia-se consideravelmente, porque elas supunham que poderíamos ofertar algum tipo de ajuda ou algum conhecimento que pudesse ajudá-las.

Durante uma abordagem, quando comunicamos para Roberto que éramos da Assistência Social, ele respondeu: "Deus que mandou vocês aqui!" - e começou a contar sua história. Havia saído da Bahia há três anos para tentar a vida em São Paulo. Trabalhou por um período de tempo, mas, tendo ficado desempregado e sem conseguir nova colocação, acabou indo para a rua. Ele dizia estar em situação de rua há seis meses. Mostrou-nos uma foto da época em que vivia, em sua terra natal. Nela, estava com sua família: mãe, irmão e avô. Observamos que sua aparência havia mudado drasticamente, nesse período de tempo: emagrecera muito, tinha perdido alguns dentes, o rosto apresentava algumas cicatrizes - sinais do tempo passado em situação de rua. Além disso, havia perdido o ar de felicidade que parecia nítido na foto. Enfim, aparentava ser outra pessoa. Contudo, este que agora encontrávamos ainda era Roberto, com a diferença de que o tempo passado em São Paulo o envelhecera uns dez anos.

Ele nos fez um pedido: precisava com urgência de 17 reais para ir a Ribeirão Preto o mais rápido possível. Dizia ter arrumado emprego na área da construção civil, onde lhe pagariam uma boa remuneração, vale-alimentação e alojamento - era tudo de que precisava para sair da rua. Suspendemos a resposta e continuamos com o atendimento, na expectativa de que houvesse outros pontos importantes em sua demanda, além daquele enunciado. Perguntamos o nome da empresa e se ele tinha documentos pessoais. Disse que já havia entregado todos os documentos na empresa e somente precisava chegar à sede naquele mesmo dia, antes das 14 horas. Encontramos
Roberto às 10 horas e deduzimos que ele teria quatro horas para chegar ao seu destino. Avaliando rapidamente, julgamos que poderíamos lhe dar o dinheiro, afinal, era disso que ele precisava para chegar a um local onde teria acesso a todos os direitos que, na rua, estavam sendo supostamente violados, referentes a trabalho, renda, habitação e outros.

Decidimos entrar em contato com a empresa, a fim de tentar estender o prazo de comparecimento, e descobrimos que a empresa não existia. Outras informações dadas por Roberto também não condiziam com a realidade: do município $\mathrm{X}$ até Ribeirão Preto eram necessárias aproximadamente oito horas, enquanto o valor da passagem não era apenas o valor solicitado por ele. Para todas as pessoas que ele abordava na rua, ele contava essa mesma história e, quando ouviu as palavras "Assistência Social", teve a certeza de que poderia receber ajuda. Continuamos com o atendimento, mas sem questioná-lo sobre a veracidade da sua demanda e, embora tivéssemos suspendido a resposta sobre sua encomenda financeira, mantivemos o atendimento e o contato, com a hipótese de que, mais tarde, poderiam surgir outras demandas.

Em outro momento, ele nos procurou para contar a parte da história que omitira no momento da sua apresentação, após perguntar se éramos da Assistência Social. Dessa vez, ele relatou os impasses enfrentados até ir para a rua, a vida no "trecho", as passagens por albergues e por outras cidades. A partir desse ponto, iniciamos efetivamente os atendimentos e outras demandas passaram a surgir, tais como: reencontrar a família, recuperar o afeto perdido, voltar ao mercado de trabalho, fazer algo a respeito do uso de álcool. Tais demandas não foram explicitadas nos primeiros atendimentos e surgiram conforme foi sendo construído o vínculo transferencial. Todo o atendimento com Roberto foi efetuado na própria rua.

Em algumas ocasiões, observávamos que as pessoas não queriam ser abordadas. Quando percebíamos que não éramos bem-vindos, apenas nos apresentávamos, deixávamos o nosso contato e endereço e rapidamente nos retirávamos. A abordagem iniciava-se como uma conversa casual. Era um trabalho de aproximação. Após a construção do vínculo, os atendimentos ocorriam em outro ritmo: os sujeitos passavam a revelar outras demandas além das iniciais, a contar suas histórias, a relatar os moti- 
vos que os levaram a ir para a rua, inclusive os que os impediam de sair.

A desconfiança faz com que a abordagem nem sequer aconteça, ou não passe da fase inicial, a qual geralmente é a da apresentação mútua. Nesses casos, os sujeitos nem chegam a direcionar alguma demanda aos trabalhadores-intercessores, porque, para tal, o vínculo é essencial. A construção do vínculo dos sujeitos com os profissionais e com os estabelecimentos institucionais começa com uma suposição: os sujeitos supõem que ali podem oferecer algo de que precisam.

Os atendimentos ocorriam na sede do CREAS e na rua, embaixo de pontes, viadutos, terrenos baldios, estacionamentos, na frente de lojas e praças. Após a primeira abordagem ou acolhimento, estabelecido o vínculo, iniciávamos os acompanhamentos. Cada integrante da equipe atendia a um número de sujeitos, tornando-se referência para eles. Isso não impossibilitava que os outros integrantes da equipe pudessem atender esses sujeitos, acompanhá-los e dar-lhes suporte, quando fosse necessário. Quando o profissional de referência entrava em férias ou se ausentava, todos sabiam o suficiente sobre o sujeito em questão, já que as reuniões de equipe aconteciam semanalmente, de forma que a pessoa continuava sendo acompanhada. Caso o trabalhador saísse do CREAS, os atendimentos continuariam, pois eram realizados coletivamente (Oury, 2009).

Atendíamos e acompanhávamos diversas demandas: mulheres grávidas em final de gestação, pessoas com o vírus HIV e/ou com doenças sexualmente transmissíveis, profissionais do sexo, sujeitos em sofrimento psíquico e com impasses nos processos de subjetivação, idosos e pessoas com deficiência que se perderam de casa, toxicômanos e alcoolistas, pessoas desempregadas, vítimas de violência e ameaçadas pelo tráfico etc. Todas essas situações tinham em comum o fato de os sujeitos estarem em situação de rua, terem pouco ou nenhum acesso aos serviços de proteção social e de outras políticas, estarem em estado de pobreza extrema e não ter um trabalho com remuneração equivalente às suas necessidades de sobrevivência.

Eram casos complexos, nos quais as ações que visassem somente a promover os encaminhamentos para inserção ao mercado de trabalho, o retorno para a família ou o referenciamento para outras políticas não eram suficientes. Os anos de rua, a baixa escolaridade, os baixos salários a que sempre estiveram submetidos e o longo tempo de uso de drogas dificultavam e, em muitos casos, impossibilitavam que arcassem com despesas básicas, tais como aluguel, alimentação e cuidado com o próprio corpo.

Havia também os sujeitos que apresentavam sofrimento psíquico e exigiam uma abordagem mais sutil e específica, principalmente com relação aos que estavam há muitos anos na rua. Muitas dessas pessoas recusavam as ofertas de abordagem da equipe ou a aproximação de qualquer pessoa que julgassem ser estranhas. Uma aproximação pensada com cautela aumentava as chances de o sujeito responder assertivamente ao contato. Às vezes, abordávamos as pessoas em situação de rua com auxílio de pessoas da comunidade ou ofertando algo que poderia ser do seu interesse imediato, como comida, dinheiro, roupa, cobertor, cigarro etc. Após a vinculação, essa oferta era suspensa. Essas ações tinham tanto o propósito aproximar a equipe de trabalhadores dos sujeitos e conhecê-los quanto nos tornar conhecidos, no território, pelas pessoas.

Certo dia, recebemos uma solicitação de abordagem nos seguintes termos: denunciaram que pessoas em situação de rua estavam ateando fogo à ponte de acesso ao único shopping do município, correndo o risco de que isso avariasse sua estrutura. Por conta disso, a Guarda Civil Metropolitana (GCM) iria até o local para desfazer os "mocós" (barracos) e desalojar as pessoas que estavam embaixo da ponte. Ainda não tínhamos feito abordagens nesse local, pois ali o consumo de drogas era intenso e, de acordo com outros trabalhadores do CREAS, os sujeitos que ali se encontravam eram muito hostis e não aceitavam o contato. Entretanto, decidimos que era preciso tentar e, se não fôssemos bem recebidos, ao menos poderíamos avisar que as forças de segurança iriam até o local e, caso ela interviesse, nós estaríamos lá para termos certeza de que não haveria truculência. Resolvemos abordá-los antes da chegada da GCM, porque ficamos com receio de que eles relacionassem nossa presença com a da Guarda, o que poderia tornar impossível um trabalho futuro no local. Contudo, sabíamos que não seria um bom primeiro contato abordá-los nessas circunstâncias.

Ao chegar, encontramos algumas pessoas conversando, uma delas já nossa conhecida, em razão do seu longo histórico de atendimento na rede de Assistência Social. Apresentamo-nos e dissemos os motivos que nos levaram até o local. Um homem, que dizia morar 
ali perto e ser vizinho da ponte, foi quem nos recebeu. Contou que não morava embaixo da ponte, mas sempre ajudava as pessoas, deixando-as tomar banho em sua casa, dando alimentação e trabalho. Dizia-se empreiteiro da construção civil. Na ocasião, achamos que ele poderia ser um parceiro importante, porque todos o respeitavam muito e o chamavam de "tio". Perguntamos sobre o fogo embaixo da ponte. Eles nos responderam que haviam acendido uma vela, esqueceram-se de apagá-la e dormiram; a consequência foi que as paredes do "mocó" e o colchão pegaram fogo. Logo, ninguém estava intencionalmente ateando fogo à alça de acesso ao shopping. Após o aviso de que a polícia iria ao local, todos nos agradeceram e disseram que seria importante que acompanhássemos a ação policial porque, da última vez na qual tinham ido ao local, os policiais mandaram que todos se deitassem com o rosto no chão e pisaram em cima deles: "Parecíamos cachorros", relataram.

No dia efetivo da ação, não havia mais nenhuma pessoa sob a ponte; passados alguns dias, todos voltaram para o mesmo lugar. A partir dessa ocasião, incluímos a ponte em nosso itinerário de atendimento e abordagens. Fizemos alguns relatórios, esclarecendo a causa acidental do fogo e o enviamos para os órgãos que o solicitaram.

A ponte, como passamos a denominar aquele local, era um espaço de intenso consumo de drogas, principalmente de crack, bastante similar à região de São Paulo denominada Cracolândia, só que em uma escala menor. Havia pelo menos mais outros dois lugares iguais a esse, no município. Segundo uma pesquisa feita pela Fundação Oswaldo Cruz (Fiocruz) (Brasil, 2013b), nas capitais brasileiras e no Distrito Federal, existem cerca de 370 mil pessoas que consomem crack e outras drogas. Desse número, aproximadamente $40 \%$ ficam em situação de rua, o que não significa especificamente que morem na rua, mas que a têm como local de convívio e referência.

Parece haver uma possível relação entre o uso de drogas e as maneiras de sobrevivência na rua, visto que o crack e o álcool demonstram auxiliar no suporte à realidade das pessoas em situação de rua. Todavia, à medida que ajudam a suportá-la, auxiliam-nas a fugir da realidade, mesmo a habitando. Não é por acaso que as toxicomanias são consideradas a fisionomia principal do sintoma social dominante (Melman, 1992). Nas circunstâncias de vida difícil das pessoas em situação de rua, a droga parece operar como um facilitador de sociabilidade, ajudando-as a interagir com outras que estão nas ruas e também com a população em geral. No entanto, quando tentam construir possibilidades de sair das ruas, a relação que os sujeitos estabeleceram com a droga dificulta seu retorno para o social instituído. Na situação de vulnerabilidade em que se encontram, tendem a cada vez mais a aumentar o seu uso de substâncias psicoativas e, quando lhes é solicitado, não conseguem facilmente ficar sem usar. $\mathrm{O}$ vínculo e a permanência em sociedade exigem que o indivíduo fique abstinente ou que controle o seu uso, a fim de poder continuar no laço social e, eventualmente, vir a ingressar no mercado de trabalho, visando à sua sobrevivência. Ações que vão na direção da redução de danos podem contribuir para minimizar os impactos na relação do sujeito consigo e com o seu contexto (Oliveira, Sampaio, \& Saldanha, 2015).

\section{Considerações gerais}

A nossa práxis com as pessoas em situação de rua, na Assistência Social, revelou os impasses e os desafios dos sujeitos, ao tentarem acessar os seus direitos sociais, apesar de estes já estarem garantidos por lei. Essa realidade complexa necessita de um trabalhador que também seja um intercessor, precavido com referenciais teórico-técnicos e ético-políticos, os quais possibilitem analisar e interceder frente às demandas dos sujeitos e dos estabelecimentos institucionais, pois o modo de o trabalhador conceber essa realidade tem relação direta com o seu modo de intervir.

O trabalho na Assistência Social não consiste apenas em abordar, atender e encaminhar os sujeitos para os serviços disponíveis na rede. Alguns casos podem exigir construções prévias, por meio de diálogo e de acordos com os estabelecimentos do território ou até mesmo a implantação de novos serviços, articulando uma rede intersetorial. Observamos que os sujeitos apresentavam um conjunto de demandas manifestas (acesso a passagem de ônibus, dinheiro, alimentação, pernoite, dentre outras), que, a princípio, aparentavam serem simples e de fácil resolução, contudo, com o decorrer dos atendimentos, desvelava-se um conjunto de demandas latentes e complexas, tais como sair da rua, "reinserção social", cuidados com a saúde, acesso ao mercado de trabalho e várias outras, as quais necessitavam de aprofundamento, porque, muitas vezes, extrapolavam as possibilidades do atendimento da Assistência Social. 
A ausência de perspectiva de futuro produz subjetividades atreladas ao presente imediato, e as ações que realizávamos não tinham como meta tirar as pessoas da rua ou reinseri-las a todo custo na vida social comum, como a sociedade esperava que fizéssemos. Nossa perspectiva de trabalho era a de que tanto a saída da rua quanto a reinserção social viriam por acréscimo, como uma consequência da implicação e do trabalho dos próprios sujeitos que vivem na rua, em um processo no qual o trabalhador-intercessor entrava como coadjuvante necessário.

O modo como a sociedade vê a população em situação de rua tem efeitos diretos na subjetividade dessa população, assim como nas maneiras como ela é considerada e tratada. O imaginário social, atualizado nos estabelecimentos da rede, continha (pre) conceitos sobre a população em situação de rua, o que dificultava a sua inserção nos serviços e na comunidade. Com as nossas intercessões, tínhamos a pretensão de, sempre que oportuno, problematizar e tentar desconstruir esses discursos. A localização do CREAS dificultava o acesso dos trabalhadores aos sujeitos e deles ao estabelecimento. Também havia ausência de ofertas que estivessem alinhadas com as demandas das pessoas em situação de rua. Isso acabava produ- zindo deslocamentos dos sujeitos para locais que oferecessem melhores oportunidades de sobrevivência.

A rua é vista por muitos sujeitos como um lugar em que é possível viver - principalmente para os que já estão nela, há muitos anos - e cada sujeito encontra uma forma de habitá-la, alguns por não conseguir visualizar outra possibilidade e, outros, por escolha ou pela impossibilidade de fazer uma escolha. Com o passar do tempo, misturam-se dificuldades com impossibilidades. Mesmo para aqueles que querem sair, isso não é tão simples; não basta levá-los para um albergue, abrigo ou para a casa de um familiar: muitos já perderam os referenciais de como permanecer no convívio social comum.

Portanto, cada caso necessita de uma abordagem singular, mesmo que a situação, de imediato, pareça semelhante a muitas outras já vivenciadas pelo trabalhador-intercessor. No trabalho com as pessoas em situação de rua, o vínculo e a implicação subjetiva e sociocultural são essenciais, além do envolvimento desejante, por parte dos sujeitos - ao menos em algum grau - o que deve incluir ainda a construção de uma direção de trabalho com as pessoas em situação de rua, concomitantemente às experiências vivenciadas no dia a dia de trabalho.

\section{Referências}

Albuquerque, C. M. C. (2009). Loucos nas ruas: Um estudo sobre o atendimento à população de rua adulta em sofrimento psíquico na cidade do Recife (Dissertação de mestrado). Universidade Federal Pernambuco, Recife, PE, Brasil.

Barbosa, A. R. (2017). Vida nua: Biopolítica na gestão da população de rua (Tese de doutorado). Universidade Estadual Paulista, Faculdade de Filosofia e Ciências, Marília, SP, Brasil.

Borysow, I. C., \& Furtado, J. P. (2013). Acesso e intersetorialidade: O acompanhamento de pessoas em situação de rua com transtorno mental grave. Physis, 23(1), 33-50. https://doi.org/10.1590/S0103-73312013000100003

Botti, N. C. L., Guimarães, C. C., Silva, M. F., Silva, A. K., Oliveira, L. C., Castro. A. C. H. O. et al. (2010). Prevalência de depressão entre homens adultos em situação de rua em Belo Horizonte. Jornal Brasileiro de Psiquiatria, 59(1), 10-16. https://doi.org/ 10.1590/S0047-20852010000100002

Brasil. Ministério do Desenvolvimento Social e Combate à Fome. (2013b). Estimativa do número de usuários de crack e/ou similares nas capitais do país. Brasília, DF: Fiocruz. Recuperado de http://portal.fiocruz.br/pt-br/content/maior-pesquisa-sobre-crack-j\%C3\%Al-feita-no-mundo-mostra-o-perfil-do-consumo-no-brasil

Brasil. Ministério do Desenvolvimento Social e Combate à Fome. (2005). Norma operacional básica NOB/SUAS. Brasília, DF: o autor.

Brasil. Ministério do Desenvolvimento Social e Combate à Fome. (2012). Norma operacional básica do sistema único da assistência social (NOB SUAS 2012). Brasília, DF: o autor.

Brasil. Ministério do Desenvolvimento Social e Combate à Fome. (2011). Orientações técnicas: Centro de referência especializado para população em situação de rua: Centro pop SUAS e a População de Rua (Vol. 3). Brasília, DF: o autor.

Brasil. Ministério do Desenvolvimento Social e Combate à Fome. (2013a). Perguntas e respostas: Serviço especializado em abordagem social: SUAS e população em situação de rua (Vol. 4). Brasília, DF: o autor. 
Brito, M. M. M. (2012). Loucos pela rua: Escolha ou contingência? Um estudo de ciências sociais e psicanálise. Curitiba, PR: CRV.

Bursztyn, M. (Org.). (2000). No meio da rua. Rio de janeiro, RJ: Garamond.

Castel, R. (1987). A gestão dos riscos: Da antipsiquiatria à pós-psicanálise. Rio de Janeiro, RJ: Francisco Alves.

Corbisier, C. (1992). A escuta da diferença na emergência psiquiátrica. In P. Amarante, \& J. R. Bezerra (Orgs.), Psiquiatria sem hospício: Contribuições ao estudo da reforma psiquiátrica (pp. 9-15). Rio de Janeiro, RJ: Relume-Dumará.

Costa-Rosa, A. (2013). Atenção psicossocial além da reforma psiquiátrica: Contribuição a uma clínica crítica dos processos de subjetivação na saúde coletiva. São Paulo, SP: Universidade Estadual da Paulista.

Costa-Rosa, A. (2008). Intercessões e análises sobre o processo de produção saúde-adoecimento atenção no campo psíquico, num território municipal: Produção de novas tecnologias para o implemento da atenção psicossocial no sistema único de saúde (monografia). Faculdade de Ciências e Letras de Assis, Universidade Estadual Paulista, Assis, SP, Brasil.

Costa-Rosa, A. (2000). O modo psicossocial: Um paradigma das práticas substitutivas ao modo asilar. In P. Amarante (Org.), Ensaios: Subjetividade, saúde mental, sociedade (pp. 141-168). Rio de Janeiro, RJ: Fiocruz.

Costa-Rosa, A. (2011). Operadores fundamentais da atenção psicossocial: Contribuição a uma clínica crítica dos processos de subjetivação na saúde coletiva (Tese de livre-docência). Faculdade de Ciências e Letras de Assis, Universidade Estadual Paulista, Assis, SP, Brasil.

Costa-Rosa, A. (2015). Por que a atenção psicossocial exige uma clínica fundada na psicanálise do campo Freud-Lacan?(monografia). Assis, SP: Universidade Estadual da Paulista.

Costa-Rosa, A. (2007). Redes de contratualidade social em sujeitos do sofrimento psíquico grave: Integrando a estratégia saúde da família e estratégia atenção psicossocial no território (monografia). Faculdade de Ciências e Letras de Assis, Universidade Estadual Paulista, Assis, SP, Brasil.

Costa-Rosa, A. (1987). Saúde mental comunitária: Análise dialética das práticas alternativas (Dissertação de mestrado). Instituto de Psicologia, Universidade de São Paulo, São Paulo, SP, Brasil.

Deleuze, G. (1992). Conversações. Rio de Janeiro, RJ: 34.

Elia, L. (2010). O conceito de sujeito (3a ed.). Rio de Janeiro, RJ: Zahar.

Escorel, S. (1999). Vidas ao léu: Trajetórias de exclusão social. Rio de Janeiro, RJ: Fiocruz.

Félix-Silva, A. V., Sales, R. C. M., \& Soares, G. P. (2016). Modos de viver e fazer arte de pessoas em situação de rua. Estudos de Psicologia (Natal), 21(1), 46-57. https://doi.org/10.5935/1678-4669.20160006

Ferraz, F. C. (2000). Andarilhos da imaginação: Um estudo sobre os loucos de rua. São Paulo, SP: Casa do Psicólogo.

Foucault, M. (2009). Vigiar e punir: Nascimento da prisão. Petrópolis, RJ: Vozes.

Frangella, S. M. (2004). Corpos urbanos errantes: Uma etnografia da corporalidade de moradores de rua em São Paulo (Tese de doutorado). Universidade Estadual de Campinas, Campinas, SP, Brasil.

Freud, S. (1988). Linhas de progresso da terapia psicanalítica. In S. Freud, Edição standard brasileira das obras psicológicas completas de Sigmund Freud (Vol. 17, 2a ed., pp. 201-211). Rio de Janeiro, RJ: Imago.

Freud, S. (1996). Recomendações aos médicos que exercem a psicanálise. In: S. Freud, Edição standard brasileira das obras psicológicas completas de Sigmund Freud (Vol. 12, pp. 121-133). Rio de Janeiro, RJ: Imago.

Goffman, E. (1990). Estigma: Notas sobre a manipulação da identidade deteriorada. Rio de Janeiro, RJ: Zahar.

Goffman, E. (2001). Manicômios, prisões e conventos (7a ed.). São Paulo, SP: Perspectiva.

Gonzalez-Rey, F. L. (2002). Pesquisa qualitativa em psicologia: Caminhos e desafios. São Paulo, SP: Pioneira.

Guareschi, P. (1996). A ideologia: Um terreno minado. Psicologia e Sociedade, 8(2), 82-94.

Justo, J. (2011). Andarilhos e trecheiros: Errância e nomadismo na contemporaneidade. Maringá, PR: EDUEM.

Justo, J. (2012). Vidas errantes: Políticas de mobilidade e experiências de espaço-tempo. Londrina, PR: Eduel.

Lacan, J. (1992). O seminário, livro 17: O avesso da psicanálise. Rio de Janeiro, RJ: Jorge Zahar.

Lacan, J. (2003). Outros escritos. Rio de Janeiro, RJ: Jorge Zahar. 
Lourau, R. (1975). A análise institucional. Petrópolis, RJ:Vozes.

Lovisi, G. M. (2000). Avaliação de distúrbios mentais em moradores de albergues públicos das cidades do Rio de Janeiro e de Niterói (Tese de doutorado). Escola Nacional de Saúde Pública, Fundação Oswaldo Cruz, Rio de Janeiro, RJ, Brasil.

Marx, K. (1984). Formações econômicas pré-capitalistas (1857-58) (4a ed.). Rio de Janeiro, RJ: Paz e Terra.

Marx, K. (2004). Manuscritos econômico-filosóficos. São Paulo, SP: Boitempo.

Martinez, M. M., Pereira, L. F. P., Barbosa. A. R., Oliveira, L. M. F., \& Pazzin, D. P. (2014). A produção e a gestão da população de rua: A trajetória de Luciene. Dilemas: Revista de Estudos de Conflito e Controle Social, 7(4), 741-767.

Mattos, R. M. (2006). Situação de rua e modernidade: A saída das ruas como processo de criação de novas formas de vida na atualidade (Dissertação de mestrado). Universidade São Marcos, São Paulo, SP, Brasil.

Mattos, R. M., \& Ferreira, R.F. (2005). O idoso em situação de rua: Sísifo revisitado. Estudos de Psicologia (Campinas), 22(1), 23-32. https://doi.org/10.1590/S0103-166X2005000100004

Mattos, R. M., \& Ferreira, R. F. (2004). Quem vocês pensam que (elas) são? Representação sobre pessoas moradoras de ruas. Psicologia \& Sociedade, 16(2), 47-58. https://doi.org/10.1590/S0102-71822004000200007

Melman, C. (1992). Alcoolismo, delinquência e toxicomania: Uma outra forma de gozar. São Paulo, SP: Escuta.

Mezan, R. (2002). Interfases da psicanálise. São Paulo, SP: Companhia das Letras.

Morin, E. (2005). Introdução ao pensamento complexo. Porto Alegre, RS: Sulina.

Nasser, A. (2001). Sair para o mundo: Trabalho, família e lazer na vida dos excluídos. São Paulo, SP: Hucitec.

Oliveira, R., Sampaio, S. S., \& Saldanha, W. S. (2015). Redução de danos no atendimento a sujeitos em situação de rua. Argumentum, 7(2), 221-234. https://doi.org/10.18315/argumentum.v7i2.10440

Oury, J. (2009.). O coletivo. São Paulo, SP: Hucitec

Rosa, A. S., Cavicchiol, M. G. S., \& Bretãs, A.C.P. (2005). O processo saúde-doença-cuidado e a população em situação de rua. Revista Latino-Americana de Enfermagem, 1(13), 576-582. https://doi.org/10.1590/S0104-11692005000400017

Rosa, C. M. M. (Org). (1995). População de rua: Brasil e Canadá. São Paulo, SP: Hucitec.

Rosa, C. M. M. (2005). Vidas de rua, destinos de muitos (Estudos Brasileiros, no 37). São Paulo, SP: Hucitec.

Santos, M. (2002). O país distorcido. In W. C. Ribeiro (Org.), O pais distorcido: O Brasil, a globalização e a cidadania (pp. 49-52). São Paulo: Publifolha.

Santos, B. S. (2006). Conhecimento prudente para uma vida decente: Um discurso sobre as ciências revisitado (2a ed.). São Paulo, SP: Cortez.

Silva, M. B. O. (2005). "Louco de rua" e a seguridade social em Porto Alegre: Da (in)visibilidade social à cidadania? (Dissertação de mestrado). Pontíficia Universidade Católica do Rio Grande do Sul, Porto Alegre, RS, Brasil.

Souza, W. A. (2015). A Assistência Social e o trabalho com as pessoas em situação de rua no CREAS: um campo de intercessão (Dissertação em mestrado). Faculdade de Ciências e Letras de Assis, Universidade Estadual Paulista, Assis, SP, Brasil.

Sposati, A. (1995). Comentário sobre as formas de atuação com a população de rua. In C. M. M. Rosa (Org.), População de rua: Brasil-Canadá (pp. 85-90). São Paulo, SP: Hucitec.

Stringheta, L. H., \& Costa-Rosa, A. (2007). O grupo intercessor: Saber e conhecimento da práxis "psi" na atenção básica. In E. P. Constantino (Org.), Percursos da pesquisa qualitativa em psicologia (pp. 145-161). São Paulo, SP: Arte \& Ciência.

Tiene, I. (2004). Mulher moradora de rua: Entre violências e políticas sociais. Campinas, SP: Alínea.

Valencio, N. F. L. S., Cardoso, B. J. P., Siena, M., \& Marchezini, V. (2008). Pessoas em situação de rua no Brasil: Estigmatização, desfiliação e desterritorialização. RBSE: Revista Brasileira de Sociologia da Emoção, 7(21), 556-605. https://doi.org/10.15448/1984-7289.2019.1.30905

Varanda, W. (2003). Do direito à vida à vida como direito (Dissertação de mestrado). Faculdade de Saúde Pública, Universidade de São Paulo, São Paulo, SP, Brasil.

Vieira, M. A. C., Bezerra, E. M. R., \& Rosa, C, M. M. (Org.). (1994). População de rua: Quem é, como vive, como é vista. São Paulo, SP: Hucitec. 
Villamarim, M. C. C. (2009). Política de assistência social e população de rua: Composição de processos de subjetivação na cidade de Belo Horizonte (Dissertação de mestrado). Pontifícia Universidade Católica de Minas Gerais, Belo Horizonte, MG, Brasil.

\section{William Azevedo de Souza}

Psicólogo. Mestre em Psicologia e sociedade pela Universidade Estadual Paulista Júlio de Mesquita Filho, Assis - SP. Brasil. Coordenador dos serviços de média complexidade população em situação de rua da cidade de Campinas. E-mail: williamazevedogta@yahoo.com.br

(iD) http://orcid.org/0000-0001-5217-7930

\section{Abílio da Costa-Rosa}

Professor Livre-docente do Departamento de Psicologia Clínica da Universidade Estadual Paulista Júlio de Mesquita Filho, Assis - SP. Brasil.

E-mail: abiliocr@assis.unesp.br

iD http://orcid.org/0000-0002-7648-0114

\section{Silvio José Benelli}

Psicólogo. Doutor em Psicologia Social pelo Instituto de Psicologia da Universidade de São Paulo, São Paulo - SP. Brasil. Professor assistente doutor no Depto. de Psicologia Clínica e no Programa de Pós-Graduação em Psicologia Universidade Estadual Paulista Júlio de Mesquita Filho, Assis - SP. Brasil.

E-mail: benelli@assis.unesp.br

iD http://orcid.org/0000-0001-8394-9331

Endereço para envio de correspondência:

Departamento de Psicologia Clínica. Avenida Dom Antônio, 2100, Parque Universitário. CEP: 19806-900. Assis SP. Brasil.

Recebido 21/12/2017

Reformulado 06/06/2018-17/09/2018

Aceito 16/10/2018

Received $12 / 21 / 2017$

Reformulated 06/06/2018-09/17/2018

Aceptado 10/16/2018

Recibido 21/12/2017

Reformulado 06/06/2018 - 17/09/2018

Aceptado 16/10/2018

Como citar: Souza, W. A., Costa-Rosa, A., \& Benelli, S. J. (2019). Possibilidades nos modos de tratar a população em situação de rua. Psicologia: Ciência e Profissão, 39, 1-17. https://doi.org/10.1590/1982-3703003189078

How to cite: Souza, W. A., Costa-Rosa, A., \& Benelli, S. J. (2019). Possibilities in the ways of treament of homeless people. Psicologia: Ciência e Profissão, 39, 1-17. https://doi.org/10.1590/1982-3703003189078

Cómo citar: Souza, W. A., Costa-Rosa, A., \& Benelli, S. J. (2019). Posibilidades en los modos de tratar a la población en situación de calle.. Psicologia: Ciência e Profissão, 39, 1-17. https://doi.org/10.1590/1982-3703003189078 